\begin{tabular}{ll} 
Balkanologie & Balkanologie \\
\cline { 1 - 2 } & Revue d'études pluridisciplinaires
\end{tabular}

Vol. VIII, $n^{\circ} 2$ | 2004

Volume VIII Numéro 2

\title{
Sivignon (Michel), Auriac (Franck), Deslondes (Olivier), Maloutas (Thomas), Atlas de la Grèce
}

Paris : CNRS / Libergéo / La Documentation française, 2003, 190 p.

\section{Bernard Lory}

\section{(2) OpenEdition}

\section{Journals}

Édition électronique

URL : http://journals.openedition.org/balkanologie/2053

DOI : 10.4000/balkanologie.2053

ISSN : 1965-0582

Éditeur

Association française d'études sur les Balkans (Afebalk)

Édition imprimée

Date de publication : 1 décembre 2004

ISSN : 1279-7952

\section{Référence électronique}

Bernard Lory, « Sivignon (Michel), Auriac (Franck), Deslondes (Olivier), Maloutas (Thomas), Atlas de la Grèce », Balkanologie [En ligne], Vol. VIII, n² 2 2004, mis en ligne le 21 janvier 2010, consulté le 17 décembre 2020. URL : http://journals.openedition.org/balkanologie/2053 ; DOI : https://doi.org/ 10.4000/balkanologie.2053

Ce document a été généré automatiquement le 17 décembre 2020.

(c) Tous droits réservés 


\title{
Sivignon (Michel), Auriac (Franck), Deslondes (Olivier), Maloutas (Thomas), Atlas de la Grèce
}

\author{
Paris : CNRS / Libergéo / La Documentation française, 2003, 190 p.
}

\section{Bernard Lory}

\section{RÉFÉRENCE}

Sivignon (Michel), Auriac (Franck), Deslondes (Olivier), Maloutas (Thomas), Atlas de la Grèce, Paris : CNRS / Libergéo / La Documentation française, 2003, 190 p.

1 Nous avons déjà eu l'occasion de saluer la parution de l'Atlas de la Roumanie, dirigé par Violette Rey ${ }^{1}$ comme un superbe outil de compréhension d'un pays balkanique. Avec celle de l'Atlas de la Grèce un horizon analogue s'ouvre pour la partie méridionale de la péninsule. Nous y trouvons la même cartographie soignée et innovante, mais plus systématiquement accompagnée de commentaires. Ceux-ci sont souvent indispensables pour la lecture de cartes aux entrées compliquées (p. ex. pp. 64, 101). Les thèmes les plus développés sont: population et démographie, agriculture et espace rural, développement urbain. Le tourisme, en revanche, n'occupe qu'une place relativement modeste (pp. 168-173) et aurait mérité une approche régionale. C'est d'ailleurs un aspect que l'ouvrage n'a pas choisi de privilégier, et il ne présente presque que des cartes figurant l'ensemble du territoire grec. Hormis la mégalopole athénienne (et dans une certaine mesure la ville de Salonique) il y a très peu de cartes régionales, ce qui exige de la part du lecteur un effort constant pour cerner les spécificités locales (la Crète, les petites îles, l'Épire, etc.) La diversité régionale de la Grèce se trouve quelque peu occultée par cette présentation. L'existence du Mont Athos se réduit à une note en bas de page (p. 30), ce qui est bien peu pour un tel particularisme! Tout comme pour le volume concernant le Roumanie, on peut aussi regretter l'« insularisation » de cartes qui font abstraction de tout l'environnement régional : les pays balkaniques voisins 
n'apparaissent presque pas; les îles de Lesbos, Chios ou Rhodes semblent perdues au bord de l'océan, comme si le littoral anatolien n'était pas leur horizon quotidien.

2 Parmi les spécificités grecques bien mises en valeur dans cet ouvrage, on peut citer la question des échanges de population en 1913-1923 ; celle de l'immigration étrangère depuis la chute des régimes communistes; le curieux phénomène de l'« agriculture à distance » qui permet à des citadins d'exploiter des olivettes n'exigeant de travail qu'à certaines périodes de l'année (pp. 110-114). De nombreux diagrammes et tableaux statistiques complètent enfin heureusement cette présentation. Cet Atlas de la Grèce a su mobiliser les efforts d'une trentaine de chercheurs grecs et français. À quand un Atlas des Balkans?

\section{NOTES}

1. Balkanologie, 5 (1-2), décembre 2001 (rubrique « notes de lectures »). 